\title{
Kualitas Fisik dan Kimia Buah Jambu 'Kristal' pada Letak Cabang yang Berbeda
}

\section{Physical and Chemical Quality of 'Crystal' Guava on Different Branch Position}

\section{Dona Rustani dan Slamet Susanto*}

Departemen Agronomi dan Hortikultura, Fakultas Pertanian, Institut Pertanian Bogor (Bogor Agricultural University), Jl. Meranti, Kampus IPB Darmaga, Bogor 16680, Indonesia Telp. \& Faks.62-251-8629353 e-mail agrohort@apps.ipb.ac.id

*Penulis Korespondensi : slmtsanto@gmail.com

Disetujui : 20 September 2018 / Published Online 06 Mei 2019

\begin{abstract}
Crystal guava cultivar is one of the fruit that has high economic value in Indonesia. The quality of the fruit is affected by fruit position in the canopy. This research aims to evaluate a physical and chemical fruit quality on the shoot emerged from primary branch, secondary branch and tertiary branch. The experiment was located in Cikabayan Experimental Field, Bogor Agricultural University, Dramaga, Bogor, West Java and Postharvest Laboratory of Agronomy and Horticulture Department from February to July 2017 using the 4year-old bearing tree. The experiment uses Completely Randomized Design with single factor that was the position of the fruit on the shoot emerged from the primary branch $(\mathrm{C1})$, secondary branch $(\mathrm{C2})$ and tertiary branch (C3) with 5 replications. The result showed that branch position had no effect on all observation parameters of physical and chemical quality (fruit diameter, fruit weight, fruit softness, fruit smoothness, total soluble solid and total titrable acid. There is tendency of the fruit on the shoot emerged from primary and secondary branch has higher weight and bigger size than the tertiary branch.
\end{abstract}

Keywords: branch position, 'crystal' guava, chemical quality, physical quality

\begin{abstract}
ABSTRAK
Jambu biji kultivar kristal merupakan salah satu buah yang memiliki nilai ekonomi yang tinggi di Indonesia. Kualitas buah dipengaruhi posisi buah dalam kanopi. Penelititan ini bertujuan untuk mempelajari kualitas fisik dan kimia buah pada tunas yang muncul pada cabang primer, sekunder dan tersier. Percobaan berlokasi di Kebun Percobaan Cikabayan, IPB Dramaga, Bogor, Jawa Barat dan Laboratorium Pascapanen Departemen Agronomi dan Hortikultura dari bulan Februari hingga Juli 2017 menggunakan tanaman jambu 'Kristal' berumur 4 tahun. Percobaan ini menggunakan metode Rancangan Acak Lengkap (RAL) dengan satu faktor yaitu letak buah pada tunas dari cabang primer $(\mathrm{C} 1)$, cabang sekunder $(\mathrm{C} 2)$ dan cabang tersier (C3) dengan 5 ulangan. Hasil penelitian menunjukkan bahwa letak cabang tidak berpengaruh terhadap semua parameter pengamatan kualitas fisik dan kimia (diameter buah, bobot buah, kelunakan buah, kemulusan buah, PTT dan TAT). Terdapat kecenderungan pada buah yang muncul pada tunas yang muncul dari cabang primer dan cabang sekunder memiliki bobot dan diameter yang lebih tinggi dibandingkan dengan cabang tersier.
\end{abstract}

Kata kunci: jambu 'kristal', posisi cabang, kualitas fisik, kualitas kimia 


\section{PENDAHULUAN}

Jambu biji merupakan produk hortikultura penting di beberapa negara tropika karena kaya akan manfaat. Hampir semua bagian tanaman jambu biji dapat dimanfaatkan. Daun jambu biji dapat menyembuhkan diare, gastroenteritis, disentri, muntah dan sakit tenggorokan serta gusi berdarah (Kamath et al., 2008) serta mengandung antibakteri (Shigella flexneri dan Vibrio cholerae) (Joseph dan Priya, 2011). Buahnya merupakan sumber yang baik untuk asam askorbik, pektin dan mineral penting, serta mengandung vitamin $\mathrm{C}$ 4 kali jumlah vitamin $C$ pada buah jeruk $(250,7$ $\mathrm{mg} / 100 \mathrm{~g}$ ) (Joseph dan Priya, 2011; Dina et al., 2014).

Tanaman yang termasuk kedalam famili Myrtaceae ini, memiliki buah berbentuk bulat sampai oval, berkulit tipis dan memiliki banyak biji yang berbentuk bulat dan bertekstur keras. Buah ini mudah didapatkan di pasar dengan harga yang relatif murah karena dapat berbuah sepanjang tahun dan banyak petani yang membudidayakannya. Jambu biji memiliki beberapa kultivar, yaitu Wijaya merah, Mega merah, Deli, Mutiara dan Kristal.

Jambu 'Kristal' merupakan mutasi dari jambu Muangthai Pak yang diperkenalkan di Indonesia oleh Misi Teknik Taiwan dan diintroduksi pada tahun 2001 di Mojokerto (Ditbenih, 2007). Beberapa keunggulan yang dimiliki jambu ini adalah jumlah biji yang kurang dari 3\%, lapisan lilin yang tebal, ukuran buah yang besar serta tekstur buah yang renyah (Kurniawan, 2015). Jambu 'Kristal' biasa dikonsumsi segar karena rasanya yang manis dan teksturnya yang renyah. Jambu ini juga disukai petani karena budidayanya yang mudah dan berbuah sepanjang tahun serta nilai jualnya yang tergolong tinggi dibandingkan jambu biji varietas lain.

Perluasan pasar konsumen yang masih terbatas untuk buah jambu segar dipengaruhi oleh kualitas buah dan rendahnya daya simpan buah (Mamede et al., 2016). Permasalahan kualitas buah yang sering dihadapi petani dalam budidaya tanaman jambu biji adalah hama dan penyakit, penanganan pascapanen yang kurang tepat (Khushk et al., 2009) serta penampilan buah yang beragam. Menurut Kader (2002) parameter kualitas produk hortikultura dapat dievaluasi dengan mengukur kualitas fisik, yaitu penampilan, tekstur dan kualitas kimia, yaitu rasa dan nilai nutrisi. Penampilan dapat dievaluasi berdasarkan ukuran buah, bentuk, warna, kilau serta cacat eksternal/internal dan kerusakan. Nimisha et al. (2013) menyatakan bahwa perbaikan kualitas buah jambu biji dilakukan untuk menghasilkan buah yang memiliki bentuk yang seragam, ukuran yang baik, serta warna kulit buah yang menarik.

Kualitas buah perlu ditingkatkan untuk meningkatkan nilai produk dan memenuhi keinginan konsumen. Pertumbuhan, hasil dan kualitas buah jambu biji untuk produksi komersial dapat dikendalikan dengan mudah dengan praktik hortikultra seperti pemangkasan dan membatasi jumlah buah per tanaman untuk hasil panen yang baik bergantung pada situasi (Lakpathi et al., 2013).

Menurut Blanke (2009), kualitas buah dapat dikendalikan dengan nisbah source-sink yang cukup. Semua bagian tanaman yang melakukan fotosintesis merupakan source dan semua bagian tanaman yang memanfaatkan hasil fotosintesis merupakan sink. Daun yang telah dewasa merupakan struktur vegetatif utama penghasil asimilat (source). Lechaudel et al. (2005). menyatakan bahwa jumlah karbohidrat yang disuplai ke buah bergantung pada jumlah yang dihasilkan oleh hasil fotosintesis daun, yang berhubungan dengan luas daun serta kapasitas dan aktivitas fotosintesis.

Berdasarkan pengamatan di lapangan buah jambu biji dapat tumbuh pada berbagai tunas yang muncul dari cabang primer, cabang sekunder sampai cabang tersier dengan ukuran yang beragam. Jumlah daun pada tunas yang muncul dari cabang primer biasanya lebih sedikit dan sebagian besar ternaungi dibandingkan jumlah daun pada tunas yang muncul pada cabang sekunder maupun cabang tersier. Penelitian ini perlu dilakukan untuk mempelajari pengaruh letak buah pada cabang yang berbeda terhadap kualitas fisik dan kimia buah jambu 'Kristal'.

\section{BAHAN DAN METODE}

Penelitian ini dilakukan pada bulan Februari sampai Juli 2017 di Kebun Percobaan IPB Cikabayan, Kampus Dramaga IPB dan Analisis mutu fisik dan kimia akan dilaksanakan di Laboratorium Pascapanen Departemen Agronomi dan Hortikultura, Fakultas Pertanian, Kampus Institut Pertanian Bogor. Bahan yang digunakan pada penelitian ini adalah tanaman jambu kristal berumur 4 tahun yang di tanam di Kebun Percobaan Cikabayan, aquades, $\mathrm{NaOH} 0.1$ $\mathrm{N}$, indikator phenoftalin dan plastik. Alat-alat yang digunakan pada penelitian ini adalah jangka sorong, penggaris, hand refractometer, pnetrometer, timbangan digital, meteran, spidol permanen, gunting pangkas dan alat budidaya pertanian. 
Penelitian ini menggunakan metode Rancangan Acak Lengkap (RAL) yang terdiri atas satu faktor yaitu letak buah pada beberapa tunas yang muncul dari: 1 . cabang primer $(\mathrm{C} 1) ; 2$. cabang sekunder (C2) dan 3. cabang tersier (C3). Masing-masing perlakuan dilakukan sebanyak 5 kali ulangan, sehingga terdapat 15 satuan percobaan. Setiap satuan percobaan terdiri atas 2 buah jambu kristal.

Penelitian ini diawali dengan pemilihan dan penandaan masing-masing dua sampai lima bunga pada masing-masing letak cabang yang telah ditentukan. Pembungkusan buah dilakukan pada saat buah berumur 4 minggu setelah bunga mekar. Pemeliharaan yang dilakukan yaitu pemupukan, pengendalian gulma, penjarangan buah, pemangkasan dan pengendalian hama dan penyakit tanaman. Pemeliharaan dilakukan untuk menjaga tanaman tetap dalam kondisi optimal untuk perkembangan buah. Pemupukan dilakukan 3 bulan sekali menggunakan pupuk TSP, KCL dan NPK mutiara. Pengendalian gulma dilakukan secara mekanik dan kimia sesuai kebutuhan. Pengendalian hama dan penyakit tanaman dilakukan secara mekanik dan kimia sesuai kebutuhan. Panen dilakukan saat buah sudah berumur 14 minggu setelah antesis atau saat kulit buah berwarna hijau cerah. Panen dilakukan pagi atau sore hari untuk menghindari kehilangan air berlebih pada buah. Buah yang telah dipanen dibawa ke laboratorium pascpanen yang selanjutnya dilakukan uji kualitas buah.

Pengamatan yang dilakukan terdiri atas perkembangan buah, kualitas fisik, kualitas kimia dan uji Organoleptik. Pengamatan perkembangan buah dilakukan setelah buah dibrongsong, diamati setiap satu minggu sekali. Parameter yang diamati pada perkembangan buah meliputi diameter horizontal buah, diameter vertikal buah, warna buah, jumlah daun, luas daun dan diameter batang. Parameter warna buah diamati secara visual dengan memberikan nilai 1, 2, 3, 4 dan 5 untuk warna hijau tua, hijau, hijau cerah, hijau kekuningan dan kuning. Pengamatan kualitas fisik dilakukan setelah buah dipanen, parameter yang diamati meliputi bobot buah, kelunakan buah, serta kemulusan buah. Pengamatan kualitas fisik buah terdiri atas, pengujian Padatan Terlarut Total (PTT) dan Total Asam Tertitrasi (TAT). Pengamatan uji organoleptik dilakukan oleh 30 panelis, dengan menggunakan lima penilaian, yaitu penampilan, rasa buah, tekstur daging buah, aroma buah dan warna daging buah. Masingmasing diskoring dengan memberikan nilai 1-4. Kriteria penilaian tersebut adalah (1) tidak suka, (2) agak suka, (3) suka dan (4) sangat suka. Buah jambu dipotong membujur dengan ketebalan 2 $\mathrm{cm}$. Satu panelis mendapat satu potong buah. Pengujian organoleptik ini dilakukan sebanyak 2 kali.

Data pengamatan yang diperoleh dianalisis untuk mengetahui pengaruh perlakuan letak cabang terhadap peubah yang diamati dengan menggunakan uji F. Dilakukan uji lanjut dengan menggunakan uji Duncan Multiple Range Test (DMRT) pada taraf $\alpha 5 \%$ jika pada uji $\mathrm{F}$ menunjukkan pengaruh yang nyata.

\section{HASIL DAN PEMBAHASAN}

\section{Kondisi Umum Percobaan}

Data ilklim pada lokasi penelitian yang diperoleh dari Badan Meteorologi dan Geofisika (BMKG 2017) wilayah Dramaga, Bogor, menunjukkan bahwa suhu rata-rata bulanan berkisar antara $25{ }^{\circ} \mathrm{C}$ sampai $26.4{ }^{\circ} \mathrm{C}$, rata-rata curah hujan bulanan berkisar antara $284 \mathrm{~mm}$ sampai $526 \mathrm{~mm}$, rata-rata kelembaban $84 \%$ sampai $88 \%$. Ketinggian lokasi penelitian yaitu $180 \mathrm{~m}$ dpl. Tanaman jambu biji dapat tumbuh dengan baik pada ketinggian 5-1200 m (Balitbu, 2014). Menurut Soetopo (1992) suhu optimum untuk pertumbuhan jambu biji adalah $23-28{ }^{\circ} \mathrm{C}$, curah hujan optimum $1000-2000 \mathrm{~mm}_{\text {tahun }}{ }^{-1}$. Kelembaban udara yang baik berkisar antara 30 50\% (Balitbu, 2014). Hal ini menunjukkan bahwa kondisi kelembaban lokasi penelitian terlalu tinggi untuk pertumbuhan tanaman jambu biji.

\section{Rekapitulasi Sidik Ragam}

Hasil rekapitulasi nilai tengah menunjukkan letak cabang tidak berpengaruh terhadap diameter horizontal buah, diameter vertikal buah, bobot buah, kelunakan, PTT, ATT dan kemulusan buah (Tabel 1).

\section{Perkembangan Buah}

Letak cabang tidak berpengaruh terhadap semua parameter perkembangan buah yang meliputi, jumlah daun, diameter cabang, diameter horizontal buah, diameter vertikal buah dan warna buah. Diameter cabang dan jumlah daun diukur pada masing-masing perlakuan yang dilakukan (Tabel 2). Rata-rata jumlah daun pada tunas berkisar antara 6 sampai 8. Rata-rata diameter tunas pada ketiga perlakuan cenderung memiliki ukuran yang sama, dengan nilai berkisar antara 4.01 sampai $4.16 \mathrm{~mm}$.

Hasil penelitian sebelumnya yang dilakukan Romalasari (2016), menunjukkan bahwa pertambahan jumlah daun dengan pengaturan leaf fruit ratio diikuti dengan pertambahan diameter horizontal dan bobot buah pada saat panen. Zhen- gui (2008) menyatakan 
Tabel 1. Hasil rekapitulasi nilai tengah parameter pengamatan pengaruh letak cabang terhadap kualitas fisik dan kimia buah jambu 'Kristal' pada 14 MSA

\begin{tabular}{|c|c|c|c|}
\hline Parameter & Kisaran & $\begin{array}{cc}\text { Nilai } \\
\text { Tengah }\end{array} \quad$ Pr>F & KK (\%) \\
\hline $\begin{array}{l}\text { Diameter } \\
\text { horizontal } \\
(\mathrm{mm})\end{array}$ & $\begin{array}{l}67.22- \\
88.13\end{array}$ & $77.060 .740^{\text {tn }}$ & 8.15 \\
\hline $\begin{array}{l}\text { Diameter } \\
\text { vertikal }(\mathrm{mm})\end{array}$ & $\begin{array}{l}51.29- \\
73.54\end{array}$ & $60.620 .123^{\text {tn }}$ & 8.43 \\
\hline $\begin{array}{l}\text { Bobot buah } \\
(\mathrm{g})\end{array}$ & $153-230$ & $204.130 .290^{\text {tn }}$ & 20.39 \\
\hline $\begin{array}{l}\text { Kelunakan } \\
\left(\mathrm{mm} 50 \mathrm{~g}^{-1} 5 \mathrm{~s}^{-}\right. \\
\left.{ }^{1}\right)\end{array}$ & $20.1-22.9$ & $21.630 .327^{\text {tn }}$ & 18.20 \\
\hline PTT ( ${ }^{\circ}$ Brix $)$ & 7.5-9.5 & $8.620 .140^{\operatorname{tn}}$ & 13.31 \\
\hline ATT (\%) & $0.20-0.26$ & $0.250 .539^{\mathrm{tn}}$ & 16.80 \\
\hline $\begin{array}{l}\text { Kemulusan } \\
(\%)\end{array}$ & $80-87.5$ & $83.680 .172^{\text {tn }}$ & 20.50 \\
\hline
\end{tabular}

Keterangan: MSA: Minggu Setelah Antesis; **berpengaruh sangat nyata pada taraf nyata $1 \%$; *berpengaruh nyata pada taraf nyata $5 \%$; tn tidak berpengaruh nyata pada taraf nyata $5 \%$

Tabel 2. Rataan diameter tunas dan jumlah daun pada cabang primer, sekunder dan tersier

\begin{tabular}{lcc}
\hline Perlakuan & Diameter Tunas $(\mathrm{mm})$ & Jumlah Daun \\
\hline C1 & 4.01 & 6 \\
C2 & 4.15 & 8 \\
C3 & 4.16 & 6 \\
\hline
\end{tabular}

Keterangan: C1: Cabang primer; C2: Cabang sekunder; C3: Cabang tersier

bahwa leaf fruit ratio optimal untuk buah jambu biji kultivar mutiara adalah 8 . Fischer et al. (2012) menyatakan bahwa leaf fruit ratio yang optimal yaitu sebesar 7 daun per buah atau luas daun sebesar $146 \mathrm{~cm}^{2}$ pada buah feijoa (Acca sellowiana-Myrtaceae).

Letak buah pada cabang tidak berpengaruh terhadap parameter pengamatan diameter horizontal dan diameter vertikal buah pada 14 MSA (Tabel 3). Diameter horizontal buah pada perlakuan cabang primer, sekunder dan tersier berkisar antara 75.45 sampai $78.56 \mathrm{~mm}$ (Gambar 1). Diameter vertikal buah memiliki nilai berkisar antara 56.47 sampai $63.13 \mathrm{~mm}$. Produksi dan kualitas buah bergantung pada keseimbangan source-sink rasio (Blanke, 2009). Daun yang telah dewasa merupakan organ fotosintesis utama penghasil asimilat. Sink merupakan organ yang membutuhkan transfer karbon, seperti bunga, kelopak bunga, buah, tunas atau akar (Blanke, 2009).

Perkembangan diameter horizontal dan vertikal buah dilakukan dari buah berumur 1 sampai 14 MSA.
Tabel 3. Pengaruh letak cabang terhadap diameter horizontal dan diameter vertikal buah pada 14 MSA

\begin{tabular}{lcc}
\hline Perlakuan & $\begin{array}{c}\text { Diameter } \\
\text { Horizontal }(\mathrm{mm})\end{array}$ & $\begin{array}{c}\text { Diameter } \\
\text { Vertikal }(\mathrm{mm})\end{array}$ \\
\hline C1 & 78.56 & 63.13 \\
$\mathrm{C} 2$ & 77.18 & 62.25 \\
$\mathrm{C} 3$ & 75.45 & 56.47 \\
\hline
\end{tabular}

Keterangan: C1: Cabang primer; C2: Cabang sekunder; C3: Cabang tersier

Pertumbuhan diameter horizontal pada 2 sampai 8 MSA terjadi secara lambat (Gambar 1). Pertambahan diameter horizontal yang lebih cepat terjadi pada 10 sampai 13 MST.

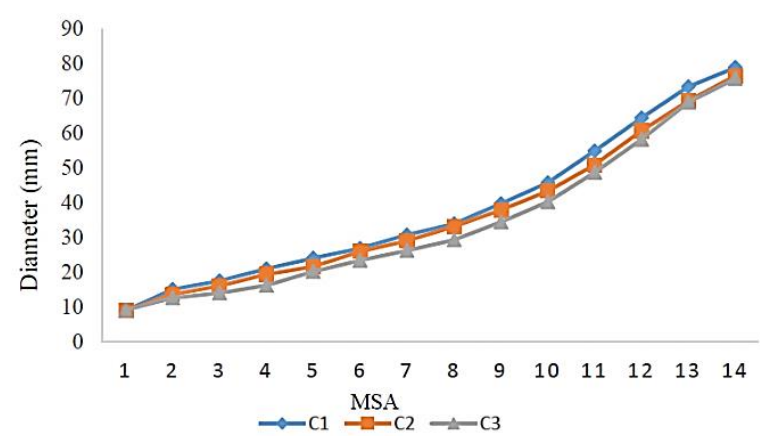

Gambar 1. Perkembangan diameter horizontal buah jambu 'Kristal' dengan perlakuan letak cabang

Pertumbuhan diameter vertikal buah secara lambat terjadi pada 3 sampai 8 MSA. Pertumbuhan diameter vertikal yang lebih cepat terjadi pada 10 sampai 13 MSA (Gambar 2). Perkembangan diameter vertikal buah pada cabang tersier pada 3 sampai 14 MSA memiliki perkembangan yang paling kecil dari perlakuan lainnya. Menurut Patel et al. (2015) waktu yang dibutuhkan buah jambu biji dari bunga antesis sampai siap panen berkisar antara 110 sampai 120 hari, bergantung pada kultivar.

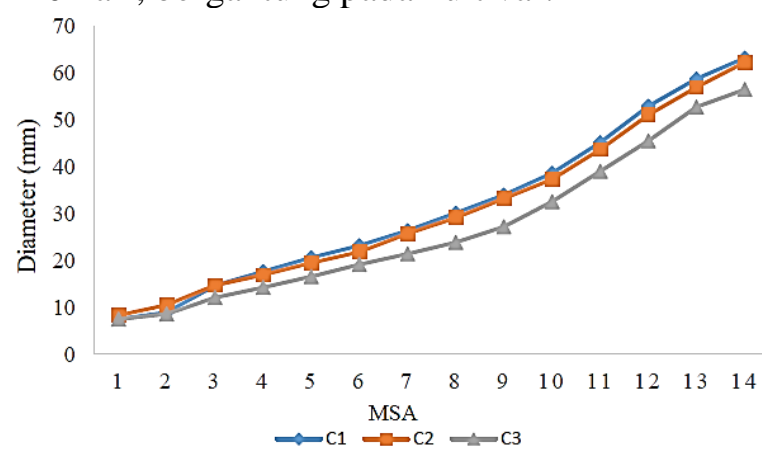

Gambar 2. Perkembangan diameter vertikal buah jambu kristal dengan perlakuan letak cabang dengan perlakuan letak cabang

Perlakuan letak cabang tidak berpengaruh terhadap warna buah. Warna buah pada 
perlakuan ketiga cabang tidak berbeda nyata pada seluruh minggu pengamatan. Rata-rata warna buah pada 3 sampai 8 MSA memiliki warna yang sama, yaitu hijau tua. Buah mulai berubah warna menjadi hijau pada 9 sampai 12 MSA. Perubahan dari warna hijau sampai hijau cerah terjadi pada 12 sampai 14 MSA (Tabel 4). Perubahan warna buah dari hijau menjadi kuning diakibatkan oleh degradasi pada korofil dan sintesis karotenoid (Ooi et al., 2016). Selama proses pematangan buah mengalami perubahan warna, tekstur dan rasa yang mengindikasikan berlangsungnya perubahan komposisi kimia (Bashir dan Abu-Goukh, 2003).

Tabel 4. Rataan warna buah ketiga cabang pada pada $4,8,12$, dan $14 \mathrm{MSA}$

\begin{tabular}{lcccc}
\hline Perlakuan & \multicolumn{4}{c}{ Warna Buah } \\
\cline { 2 - 5 } & 4 MSA & 8 MSA & 12 MSA & 14 MSA \\
\hline C1 & 1 & 1 & 2 & 3 \\
C2 & 1 & 1 & 2 & 3 \\
C3 & 1 & 1 & 2 & 3 \\
\hline Rataan & 1 & 1 & 2 & 3 \\
\hline
\end{tabular}

Keterangan: C1: Cabang primer; C2: Cabang sekunder; C3: Cabang tersier; Warna, 1: Hijau Tua; 2: Hijau; 3: Hijau cerah; 4: Hijau Kekuningan

\section{Kualitas Fisik}

Kualitas fisik buah diukur pada 14 MSA. Letak buah pada cabang tidak berpengaruh terhadap bobot buah, kelunakan buah dan kemulusan buah (Tabel 5). Nilai bobot buah pada cabang primer, sekunder dan tersier berkisar antara 181.01 sampai $217.81 \mathrm{~g}$. Bobot buah pada cabang primer $(217.81 \mathrm{~g})$ cenderung lebih besar dari cabang tersier (181.01 g). Hal ini diduga karena cabang primer memiliki diameter cabang yang lebih besar dibandingkan dengan cabang sekunder dan tersier. Diameter cabang primer yang lebih besar diduga memiliki peran yang lebih besar dalam mendukung perkembangan buah (yang berada didekatnya) dibandingkan dengan cabang sekunder dan tersier. Loescher et al. (1990) menyatakan bahwa simpanan karbohidrat biasa ditemukan pada bagian menahun tanaman, seperti akar dan batang.

Tabel 5. Pengaruh letak cabang terhadap kualitas fisik buah pada 14 MSA

\begin{tabular}{lccc}
\hline Perlakuan & \multicolumn{3}{c}{ Kualitas Fisik Buah } \\
\cline { 2 - 4 } & $\begin{array}{c}\text { Bobot } \\
(\mathrm{g})\end{array}$ & $\begin{array}{c}\text { Kelunakan } \\
\left(\mathrm{mm} \mathrm{50g}^{-1} 5 \mathrm{~s}^{-1}\right)\end{array}$ & $\begin{array}{c}\text { Kemulusan } \\
\text { Buah }(\%)\end{array}$ \\
\hline $\mathrm{C} 1$ & 217.81 & 21.10 & 87.17 \\
$\mathrm{C} 2$ & 213.59 & 21.46 & 82.50 \\
$\mathrm{C} 3$ & 181.01 & 22.33 & 82.67 \\
\hline
\end{tabular}

Keterangan: C1: Cabang primer; C2: Cabang sekunder; C3: Cabang tersier

Kelunakan buah tidak dipengaruhi oleh letak cabang. Nilai kelunakan buah berkisar antara

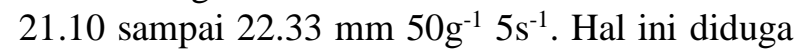
karena kelunakan buah dipengaruhi oleh tingkat kematangan buah. Kelunakan buah dapat menjadi indikasi tingkat kematangan buah (Rajkumar et $a l$. , 2016). Pelunakan buah selama pematangan buah jambu biji diikuti dengan menurunnya jumlah total pektin (Mamede et al., 2016). Pektin merupakan substansi yang mengatur kekerasan buah jambu biji pada masa awal perkembangan buah (Carvalho et al., 2009).

Nilai kemulusan buah pada perlakuan cabang berkisar antara 82.50 sampai $87.17 \%$. Kemulusan buah tidak dipengaruhi oleh letak cabang. Nilai kemulusan yang mencapai $87.17 \%$ diperoleh karena dilakukannya pembrongsongan. Menurut Noorbaiti et al., (2013), buah yang tidak dibrongsong akan terserang hama dan penyakit yang akan mengakibatkan buah busuk dan rontok.

\section{Kualitas Kimia}

Letak cabang tidak berpengaruh terhadap kandungan PTT dan ATT buah jambu 'Kristal'. Nilai PTT buah berkisar antara 8.29 sampai 9.23 obrix. Nilai ATT buah cenderung memiliki nilai yang sama, yaitu berkisar antara 0.22 sampai 0.23 $\%$. Kandungan kimia buah dipengaruhi oleh tingkat kemasakan buah. Perubahan fisiologi, biokimia dan struktural dalam jumlah yang besar terjadi selama pematangan buah, termasuk degradasi pati atau polisakarida lain, produksi gula, sintesis pigmen dan senyawa volatil serta pelarutan sebagian dinding sel (Dolkar et al., 2017).

Tabel 6. Pengaruh letak cabang terhadap kualitas kimia buah pada 14 MSA

\begin{tabular}{lcc}
\hline Perlakuan & \multicolumn{2}{c}{ Kualitas Kimia } \\
\cline { 2 - 3 } & PTT ('brix) & ATT $(\%)$ \\
\hline C1 & 8.29 & 0.23 \\
C2 & 8.35 & 0.23 \\
C3 & 9.23 & 0.22 \\
\hline
\end{tabular}

Keterangan: C1: Cabang primer; C2: Cabang sekunder; C3: Cabang tersier

Nilai PTT buah jambu pada penelitian ini diukur dan dipanen dengan penampilan kulit berwarna hijau cerah. Nilai kisaran hasil pengujian PTT dan ATT setara dengan penelitian Widodo et al. (2012), bahwa nilai PTT jambu 'Kristal' sebesar 9.83 'brix dan kandungan ATT sebesar $0.23 \%$.

\section{Uji Organoleptik}

Pengujian organoleptik buah jambu 'Kristal' dilakukan oleh 30 panelis. Penilaian menggunakan skoring dengan skala yang diberikan pada sampel yaitu tidak suka, agak 
suka, suka dan sangat suka dengan skor 1, 2, 3 dan 4. Batas penerimaan konsumen ada pada skor 2 yang berarti agak suka. Nilai standar deviasi berkisar antara 0.3 sampai 0.6 yang berarti sampel yang digunakan cukup homogen.

Hasil pengujian tingkat kesukaan panelis pada penampilan buah jambu 'Kristal' berkisar antara 2.9 sampai 3.3, yang berarti panelis menyukai penampilan buah pada ketiga perlakuan (Gambar 3). Skor kesukaan panelis pada warna buah berkisar antara 3.0 sampai 3.2. Skor yang diberikan panelis terhadap tekstur buah berkisar antara 3.1 sampai 3.4. Nilai kesukaan panelis pada aroma buah berkisar antara 2.8 sampai 3.1. Nilai kesukaan panelis pada rasa buah berkisar antara 3.1 sampai 3.4. Penilaian secara keseluruhan buah, panelis menyukai buah pada tunas yang muncul dari cabang primer, sekunder dan tersier.

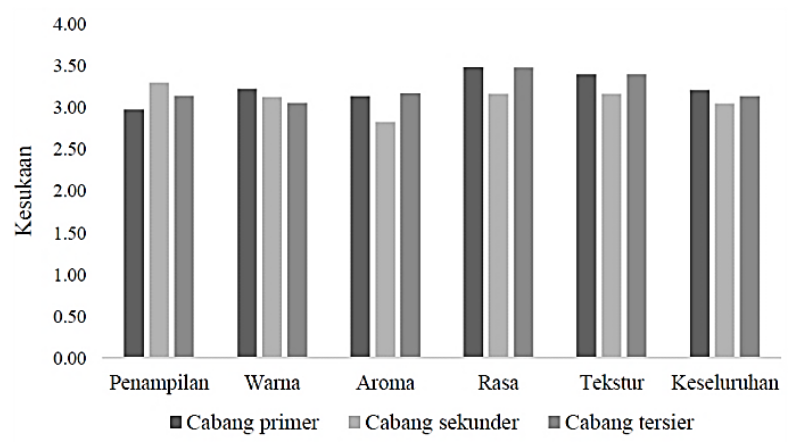

Gambar 3. Nilai uji penampilan, warna, aroma, rasa, tekstur dan keseluruhan buah pada cabang primer, sekunder dan tersier

Parameter kualitas produk hortikultura dapat dievaluasi dengan mengukur kualitas fisik dan kimia seperti penampilan, tekstur, rasa dan nilai nutrisi (Kader, 2002). Warna buah merupakan faktor paling penting dalam menentukan penerimaan konsumen (Romalasari, 2016). Menurut Ooi et al. (2016) aroma merupakan komponen utama pada rasa buah yang berpengaruh terhadap persepsi konsumen dan dianggap sebagai atribut penting untuk analisis sensori kualitas buah.

\section{KESIMPULAN}

Hasil penelitian ini menunjukkan bahwa buah pada tunas yang muncul dari cabang primer, sekunder dan tersier tidak berbeda nyata pada diameter horizontal buah, diameter vertikal buah, bobot buah, kelunakan buah dan kemulusan buah (kualitas fisik buah), serta PTT dan ATT buah (kualitas kimia). Hasil uji organoleptik menunjukkan bahwa letak cabang tidak memberikan pengaruh nyata terhadap penampilan, warna, aroma, rasa, tekstur dan keseluruhan buah. Terdapat kecenderungan buah yang tumbuh pada tunas yang muncul dari cabang primer dan cabang sekunder memiliki bobot dan diameter yang lebih tinggi dibandingkan dengan cabang tersier.

\section{DAFTAR PUSTAKA}

[Balitbu] Balai Penelitian Tanaman Buah Tropika. 2014. Budidaya jambu biji. http://hortikultura. litbang.pertanian.go.id/. [12 Agustus 2017].

Bashir, H.A., A.B.A Abu-Goukh. 2003. Compositional changes during guava fruit ripening. Food Chemistry. 80(4):557-563.

Blanke, M.M. 2009. Regulatory mechanisms in source sink relationships in plants - a review. Acta Hort. 835:13-20

Carvalho, A.B., S.A. De Assis, K.M.C. Leite, E.E. Bach, O.M. Oliveira. 2009. Pectin methylesterase activity and ascorbic acid content from guava fruit, cv. Predilecta, in different phases of development. Int. J. Food Sci. Nutr. 60(3):255-65.

Dina, O.M.A., R.A. Abdelhalim, B.B. Elrakha. 2014. Physicochemical and nutritional value of red and white guava cultivars grown in Sudan. JAAS. 2(2):27-30.

[Ditbenih] Direktorat Perbenihan Hortikultura. 2007. Deskripsi jambu biji varietas Kristal. http://varitas. net /db varietas/deskripsi/ 3136.pdf. [Mei 2017]

Dolkar, D., P. Bakshi, M. Gupta, V.K. Wali, R. Kumar, T.K. Hazarika, D. Kher. 2017. Biochemical changes in guava (Psidium guajava) fruits during different stages of ripening. Indian Journal of Agricultural Science. 87(2): 257-260.

Fischer, G., P.J. Almanza-Merchan, F. Ramirez. 2012. Source-sink relationship in fruit species-a review. Rev. Colomb. Cienc. Hortic. 6(2): 238-253

Kader, A.A. 2002. Quality parameters of fresh-cut fruit and vegetable products. In $\mathrm{O}$. Lamikanra (ed.). Fresh-cut Fruit and Vegetable Product. CRC Press. Boca Raton, Florida.

Kamath, J.V., N. Rahul, C.K.A. Kumar, S.M. Lakshmi. 2008. Psidium guajava L: a review. Int. J. Green Pharmacy. 2(1).

Khushk, A.M., A. Memon, M.I. Lashari. 2009. Factors affecting guava production in 
Pakistan. J. Agric. Res. 47(2).

Kurniawan, D. 2015. Mengenal jambu kristal. Direktorat Jenderal Hortikultura Kementrian Pertanian Indonesia https://www.google. co.id/url? $\mathrm{sa}=\mathrm{t} \& \mathrm{rct}=\mathrm{j} \& \mathrm{q}=\&$ esrc $=\mathrm{s} \&$ source $=\mathrm{w}$ eb\&cd $=1 \&$ cad $=$ rja\&uact $=8 \&$ ved $=0$ ahUKE wiz9NfTrvnXAhVLuY8KHdEfDHQQFggs MAA\&url=http\%3A\%2F\%2Fho rtikultura. pertanian.go.id\%2F\%3Fp\%3D354\&usg=AO vVaw1Jz6T29XQ4P6n8_W8xk4nM. [31 Desember 2016].

Lakpathi, G., M. Rajkumar, R. Chandrasekhar. 2013. Effect of pruning intensities and fruit load on growth, yield and quality of guava (Psidium guajava L.) cv. Allahabad safeda under high density planting. Int. J. Current Research. 5(12): 4083-4090.

Lechaudel, M., M. Genard, F. Lescourret, L. Urban, M. Jannoyer. 2005. Modeling effects of weather and source-sink relationship on mango fruit growth. Tree Physiology. 25: 583-597

Loescher, W.H., T. McCamant, J.D. Keller. 1990. Carbohydrate reserves, translocation, and storage in woody plant roots. HortScience. 25(3).

Joseph, B., M. Priya. 2011. Review on nutritional, medicinal and pharmacological properties of guava (Psidium guajava Linn.). Int. J. Pharma and Bio Science. 2(1).

Mamede, A.M.G.N., H.T.G. Barboza, A.G. Soares, A.C.V. Neves Jr., M.J.O. Fonseca. 2016. Postharvest physiology and technology for fresh guavas. In S.D. Todorov, C.S. Bogsan, (eds.). Tropical Fruits. Nova Science Publisher. New York.

Nimisha, S., D. Kherwar, K.M. Ajay, B. Singh, K. Usha. 2013. Molecular breeding to improve guava (Psidium guajava L.): current status and future prospective. Scientia Horticulturae. 164: 578-588.
Noorbaiti, I., S. Trisnowati, S. Mitrowiharjo. 2013. Pengaruh warna dan umur pembrongsongan terhadap mutu buah jambu biji (Psidium guajava L.). Vegetalika. 2(1): 44-53.

Ooi, S.Y., M.K. Ong, B. Kunasundari. 2016. Mango and guava: nutrition and postharvest physiology. In S.D. Todorov, C.S. Bogsan (eds.). Tropical Fruits. Nova Science Publisher. New York.

Patel, R.K., C.S. Maiti, B.C. Deka, N.A. Deshmukh, V. K. Verma, A Nath. 2015. Physical and biochemical changes in guava (Psidium guajava L.) during various stages of fruit growth and development. IJAEB. Vol. 8(1): 75-82.

Rajkumar, G. Kaur, A. Mann, C. Lata, A. Singh, A. Kumar. 2016. Biochemical changes in guava (Psidium guajava) cv. Allahabad Safeda fruits as a function of maturity stages. Indian J. Agric. Science. 86(12): 1595-1600

Romalasari, A. 2016. Perbaikan kualitas jambu biji (Psidium guajava L.) var kristal dengan pengaturan leaf fruit ratio dan pemberongsongan buah. [Tesis]. Institut Pertanian Bogor. Bogor.

Soetopo, L. 1992. Psidium guajava L. In E. W.M. Verheij, R.E. Coronel (eds.). PROSEA. Edible Fruits and Nuts. Pudoc, Wageningen. 266-270.

Widodo, S.E., Zulferiyenni, M. Icha. 2012. Pengaruh penambahan indole acetic acid (IAA) pada pelapisan kitosan terhadap mutu dan masa simpan buah jambu biji (Psidium guajava L.). 'Crystal'. J. Agrotropika. 17(1): 14-18.

Zhen-gui, O.U. 2008. Study on suitable fruit load of pearl guava. J. AAS. Vol. 35: 1541115413. 